\title{
Improving engagement with biomechanics: student perspectives and a professional development initiative
}

\section{Sarah P Shultz ${ }^{1}$}

Kinesiology Department, Seattle University

$90112^{\text {th }}$ Avenue, Seattle, WA 98122

shultzsarah@seattleu.edu

\section{Sarah-Kate Millar}

Sports Performance Research Institute New Zealand (SPRINZ), School of Sport and Recreation, Auckland University of Technology, Auckland, New Zealand

Private Bag 92006, Auckland Mail Centre, Auckland, New Zealand

skmillar@aut.ac.nz

\section{Philip W Fink}

School of Sport, Exercise, and Nutrition, Massey University

Massey University Manawatu (Turitea)

Tennent Drive

Palmerston North 4474

New Zealand

p.fink@massey.ac.nz

\section{Kim Hébert-Losier}

Division of Health, Engineering, Computing and Science

School of Health, Sport and Human Performance

University of Waikato, Adams Centre for High Performance

52 Miro Street, Mount Maunganui

Tauranga, 3116, New Zealand

kim.hebert-losier@waikato.ac.nz

\section{Geoffrey Handsfield}

Auckland Bioengineering Institute

University of Auckland

70 Symonds St, Level 6

Auckland 1010, New Zealand

g.handsfield@auckland.ac.nz

ASME Membership: N/A

\section{Kelly Sheerin}

\footnotetext{
${ }^{1}$ Corresponding author
} 
Sports Performance Research Institute New Zealand (SPRINZ), School of Sport and Recreation, Auckland University of Technology, Auckland, New Zealand

Private Bag 92006, Auckland Mail Centre, Auckland, New Zealand

kelly.sheerin@aut.ac.nz

\section{Denny Wells}

Sports Performance Research Institute New Zealand (SPRINZ), School of Sport and Recreation, Auckland University of Technology, Auckland, New Zealand

Private Bag 92006, Auckland Mail Centre, Auckland, New Zealand

Denny.wells@aut.ac.nz

\section{Jenny Clarke}

School of Health Sciences, University of Canterbury

Private Bag 4800, Christchurch 8140, New Zealand

Jenny.Clarke@canterbury.ac.nz

\section{ABSTRACT}

Student engagement is an essential aspect of educational environments, and this is especially true for Science, Technology, Engineering, and Mathematics (STEM) disciplines, where student engagement declines in middle and high school years. Techniques for bolstering student engagement, such as hands-on learning, may be especially effective in the field of biomechanics since this discipline is rooted in STEM and has fundamental applications to everyday movement. To this end, this paper describes 1) the perceptions of student teachers in their first year of tertiary (undergraduate) education regarding the biomechanics content from their secondary (high school) education, and 2) a professional development initiative, in the form of a discipline specific teacher training workshop, to enhance biomechanics resources for teachers via peer networking. The perception of student teachers in their first year of tertiary education in teaching indicated a positive relationship between perception of secondary school teaching quality and selfconfidence with specific biomechanical concepts. Open responses focused on the need to cover concepts thoroughly, using practical activities where possible, and taking time to ensure understanding before progressing to more advanced concepts. The teacher training workshop provided secondary school Physical Education teachers with an opportunity to network nationally with other teachers across New 
Journal of Biomechanical Engineering

Zealand, and internationally with university-based biomechanics researchers. Peer focus groups helped to design and refine sets of experiential learning activities that could be easily implemented in the classroom.

\section{INTRODUCTION}

'Student engagement' is a term that has been popularized, referring to the quality of a student's involvement in pedagogical environments $[3,2]$. While youth engagement in Science, Technology, Engineering, and Mathematics (STEM) disciplines is fundamental to success across multiple workforces [3], research has shown that this engagement declines over middle and high school years [7]. For students, it is not only the subject matter, but also how teachers address and present this content which contributes strongly towards successful engagement and learning [1]. For teachers, their support networks, enjoyment of teaching, and personal efficacy have been identified as important for fostering student engagement [6]. Interactive activities have been identified as successful tools for increasing engagement, particularly in science disciplines [3].

Biomechanics is specifically identified within the New Zealand Health and Physical Education curriculum (Te Kete Ipurangi TKI Levels 5-8) as an example of how students will apply scientific and technological knowledge to enhance physical abilities and improve performance [8]. However, previous research suggests that there might be a disconnect between how Physical Education teachers are teaching biomechanics and the intentions of the New Zealand curriculum [4]. The New Zealand curriculum and the National Certificate of Educational Achievement (NCEA) favor a constructivist approach to Physical Education pedagogy, but this is not reflected as strongly in the actual practice of teaching [4]. Specifically, biomechanics is a discipline that is well positioned 
for hands-on, student-centered learning; but it is often the teacher's discomfort with biomechanical content that prohibits more engaged interaction $[4,5]$ and can ultimately hinder student learning.

Professional development is often considered important to assist teachers in becoming more effective in the classroom [6]. Within the biomechanics discipline, professional development in the form of teacher training workshops could provide a forum for simultaneously increasing teacher confidence with biomechanical content and aligning biomechanics pedagogy with the formal curriculum.

This paper describes 1 ) the perceptions of student teachers in their first year of tertiary (undergraduate) education regarding the biomechanics content from their secondary (high school) education, and 2) a professional development initiative, in the form of a discipline specific teacher training workshop, to enhance biomechanics resources for teachers via peer networking.

\section{SURVEY OF STUDENT TEACHER PERCEPTIONS Participants}

Student teachers, i.e. undergraduate students majoring in Physical Education, ( $n$ = 52; 31 female, 21 male; age: $19.2 \pm 1.8$ years) completed an introductory survey prior to entering their first year of tertiary study in a Physical Education teacher training program in New Zealand. All participants had been out of formal secondary education for less than 5 years. Seventeen participants graduated from single-sex secondary schools, and the remaining 35 participants had attended co-educational secondary schools. The majority of students $(n=44)$ completed National Certificate of Educational Achievement (NCEA) level 3 (i.e., the highest level of secondary school, equivalent to 
high school graduation). When asked specifically if they had formally studied biomechanics during their secondary education, $90 \%$ indicated they had, while $6 \%$ said no, and the remaining $4 \%$ were unsure.

\section{Methods}

The survey (see supplementary material) gathered demographic data and information about the student teachers' self-identified exposure to seven biomechanical concepts (projectile motion, levers, Newton's laws, balance and stability, kinematics, angular motion, and energy) during secondary school [8]. All student teachers provided signed informed consent prior to completing the survey. The survey was approved by the university human ethics committee.

Quantitative and qualitative analyses were used to interpret the survey data.

Questions of main interest were those surrounding perceived confidence in specific biomechanics topics and perceptions relating to how well these concepts were taught in secondary school. A 5-point Likert scale was used for questions on perception, and responses were coded 1 (low perceptions) to 5 (high perceptions). Correlation analysis was used to analyze the relationship between students' confidence levels and their perceptions of how well they were taught, with a significance level set at $p<0.01$. Open response questions were used to describe attributes of secondary school teachers, teaching qualities that contributed to the perceived confidence of student teachers in specific biomechanics topics, and perceptions relating to how well these concepts were taught. Themes were derived from the responses.

\section{Responses to Survey}




\section{Perceptions of Education}

Perceived quality of teaching in the student teachers' secondary school education, and their current confidence in each of the seven biomechanical concepts is outlined in

Figure 1. The majority of student teachers believed that they had studied all seven concepts, although positive response rates varied from 63\% (angular motion) to $90 \%$ (Newton's laws). There was discernibly more variation in perceptions of how well each concept was taught, with 'balance and stability' and 'Newton's laws' having more positive ratings than topics on 'energy' and (linear or angular) 'motion'. Similar patterns arose in the perceived confidence scores, with student teachers feeling more confident about their mastery of topics such as 'balance and stability', and less confident about mastery of 'energy' and 'kinematics'. The similarity in patterns between the confidence of student teachers and their perceptions on how well concepts were taught was reflected in the correlational analysis, where a significant positive relationship was found between measures $(r=0.763 ; p<0.001)$.

\section{Educational Attributes Contributing To Perceived Confidence}

Three major themes arose from the open response questions: time; demonstrations and/or practical examples; and class size and/or individual attention.

\section{Time}

Approximately half (49\%) of responses concerned the amount of time devoted either to teaching biomechanics or to teaching specific biomechanical concepts. Two thirds of the responses related to 'time', and suggested that insufficient time was devoted to 
teaching specific concepts. Student teachers who expressed these sentiments reported feeling inadequate command of the concept. Specific comments included:

"The lecturer was good however I seem to remember a lot being crammed into a small amount of time, so it was quite rushed."

"My Physics teacher had a good understanding of Physics but taught at a high speed making it hard to learn enabling me to only know the topics up to an Okay level."

"The things I marked 'poorly' were things we basically didn't spend time on or go into depth with it."

By contrast, the remaining third of responses related to 'time' praised their teachers for ensuring students had mastered the material before progressing to more advanced or other topics. These comments were mostly reported by students who rated higher perceived confidence across the key biomechanical concepts. Examples of these comments relating to time included:

"My science teacher broke down the skills and helped us to understand it in an easier form and did lots of study with us to help us."

"He spent a decent amount of time on the topic and made sure that everyone had a good understanding of the topic before moving onto the next."

"Some teachers also made time available so that if we were having trouble we could go and see them to get help."

\section{Demonstrations and/or practical examples}

Approximately half (49\%) of the open responses related to demonstrations and practical activities being used to teach biomechanics. The majority of these comments were 
strongly linked to responses around confidence and teaching quality in key biomechanical concepts. Over one-third (39\%) of the overall responses related to understanding and learning being supported by practical demonstrations, such as practically applying biomechanical concepts in sports. Specific comments included: "Lots of demonstrations and examples particularly with projectile motion when we played golf to further our understanding. Same goes with balance and stability, by using physical examples it's easier to remember and understand."

"The things that worked well were put things into scenarios that I related to help me understand and using demonstrations, and also using repetition and asking me lots of questions to ensure I understood the concepts."

"Being taught with a mixture of visual and oral teaching styles helped to increase understanding. Using examples relating to sports etc."

Ten percent of the open responses suggested learning was limited by a lack of practical activities or links to everyday applications. These responses were often linked to other open responses concerning limitations in available time.

\section{$\underline{\text { Class size and/or individual attention }}$}

Several student teachers' comments related to class size and efforts of the teacher to ensure that each individual had a good understanding of the concepts covered. Large class sizes and students talking in larger groups were perceived negatively, while positive comments identified teachers working with small groups and ensuring individuals had a good understanding of the current topic. 
"Didn't move on to other subjects until the majority of the class were able to understand the basics."

"Small class and had great demonstrations so that we could physically see or feel what was happening."

Some participants praised the subject knowledge of the teachers, suggesting command of the material related to the teacher providing creative resources and using a variety of ways to explain biomechanical concepts. Three comments also related to the ability of the teacher to simplify the information to make it easier to interpret. Conversely, comments suggested that some teachers assumed too much prior knowledge, or did not simplify/clarify material to aid learning:

"Teachers knowledge was extremely high and had the patience to teach, I found that sometimes the explanation could have been simplified for a better understanding for my learning."

\section{TEACHER TRAINING WORKSHOP}

The teacher training workshop was designed to address two of the themes identified in the open responses of the student survey: practical activities and subject knowledge of the teachers. The workshop was a collaborative project between the New Zealand National Biomechanics Day council and the International Society of Biomechanics in Sports (ISBS) conference organizing committee. The objective of the workshop was to provide secondary school teachers with the opportunity to work side by side with international biomechanics researchers, while also networking with other Physical Education teachers from around New Zealand. Topics aligned closely with the 
biomechanical concepts identified in the survey: balance, motion, flight, levers, and injury prevention.

Consultation took place with leading physical education teachers on the structure and content of the workshop. Their answers resulted in three key outcomes:

1. Provide a specialized professional development day focused on biomechanics led by key presenters in the field, who were also presenting at the ISBS annual conference.

2. Facilitate small working groups to help teachers upskill their knowledge in a single biomechanics area, design teaching and learning activities for their students, and provide networking opportunities for teachers from around the country.

3. Develop and provide a secondary school teaching resource compiling the activities designed during the workshop covering five key biomechanics topic areas.

The workshop was marketed (see Supplemental Material for promotional flyer) through social media, teaching associations, and email. Travel scholarships were awarded to teachers who were attending from outside of the Auckland metropolitan area. Ninety Physical Education teachers registered for the event and 20 scholarships were awarded. In addition to the attendees, key researchers within the ISBS and New Zealand biomechanics communities were invited directly to participate in the workshop as expert leaders for each group. The expert leaders were assigned one of the five biomechanics concepts and were asked to prepare introductory material and review emerging research for their assigned topic. Graduate students were also recruited to 
work with each group, and to take notes during the workshop that would ultimately be compiled into the teaching resource.

The workshop itinerary began with a welcome discussion about ISBS, New Zealand National Biomechanics Day, and additional online support materials available to teachers in the area of biomechanics. Teachers were then divided into one of five preassigned groups, based on teachers' pre-defined area of interest. Each group received an overview of the topic, covering key points and latest research by a lead biomechanics university lecturer and researcher in the field. This presentation also included topicspecific teaching ideas. The groups then broke into further three sub-groups to design teaching and learning activities for levels one, two, or three Physical Education students. Sub-groups were then combined within the same educational level to facilitate the sharing of ideas across topic areas. Sub-groups also presented their activities and received feedback from their peers, as well as from the biomechanical experts. A resource was compiled of all activities for distribution to attending teachers.

Surveys were administered directly after the event before the resource was distributed, and then seven months post-event after distribution of the resource. The immediate follow-up survey had a completion rate of $70 \%$ and three key themes emerged: learn from others; networking; and new knowledge (specific feedback, Table 1). The seven month post workshop follow-up survey had poor completion rates (less than $10 \%$ ), and meaningful analysis could not be conducted.

\section{DISCUSSION}


This paper described student teacher perspectives on learning biomechanics principles in secondary school, and a professional development initiative to strengthening teacher efficacy within the sub-discipline. There was a strong relationship between student teachers' self-reported perceptions of understanding of the biomechanical concepts, and positive responses to learning experiences in secondary school. Additionally, responses in the open-ended questions linked positive learning experiences to time spent on each topic, pedagogical approaches through practical activities and demonstrations, and efforts by teachers to ensure mastery of concepts by individuals. Teacher support and practical applications have previously been identified as factors influencing student engagement [3]. Fredricks et al. [7] conducted semi-structured interviews to enhance understanding of when middle and high school students were engaged during science and mathematics classes. The researchers found higher student engagement when working with classmates on experiential learning activities, while more 'teacher-directed environments' that primarily involved lectures were less engaging. Similar findings were seen in the open responses of the student surveys described here.

The emphasis on pedagogical approaches through practical activities and demonstrations was a driving factor in the development of the teacher workshop. Several open responses focused on the ideas and activities that were discussed. However, to successfully develop these ideas for immediate application to classroom curriculum, prompt distribution of the resources is necessary. The presence of teachers from a varied background received significant positive feedback from the post-event 
survey, as many teachers commented on the opportunity to network with other teachers. The perspectives of both student teachers and current secondary school teachers suggest that group work and networking, combined with experiential learning opportunities, are fundamental components to engagement and competency within the biomechanics discipline.

\section{ACKNOWLEDGMENT}

The authors would like to acknowledge the contributing experts (Laura-Anne Furlong, Duane Knudson, Suzie Belcher, Chloe Mckenzie, Chris Whatman, Denise Atkins) and students (Mostafa Yaghoubi, Craig Birkbeck, Miriama Beratabua, Katrina Sharlott, Jessica Yeoman) who volunteered their assistance for the teacher training workshop. Support from the Tarn Group, Auckland University of Technology, and International Society of Biomechanics in Sports should also be acknowledged.

\section{FUNDING}

The teacher training workshop was supported by the Ministry of Business, Employment, and Innovation as part of the Unlocking Curious Minds scheme (grant ID MAUX1710). 


\section{REFERENCES}

[1] National Research Council and Institute of Medicine, 2004, Engaging Schools, Washington, DC, The National Academies Press.

[2] Eccles, J. S., and Wang, M., 2012, "Part I commentary: So what is student engagement anyway," Handbook of research on student engagement, S. L. Christenson, A. L. Reschly and C. Wylie, eds., Springer Sciences, New York.

[3] Fredricks, J. A., Hofkens, T., Wang, M.-T., Mortenson, E., and Scott, P., 2018, "Supporting Girls' and Boys' Engagement in Math and Science Learning: A Mixed Methods Study," Journal of Research in Science Teaching, 55 (2), 271-298.

[4] Fyall, G., 2016, "Biomechanics, the health and physical education curriculum and Confucius? Considerations for teaching, learning and assessment," Curriculum Matters, 12, 82-108.

[5] Knudson, D., Noffal, G., Bauer, J., McGinnis, P., Bird, M., Chow, J., Bahamonde, R., Blackwell, J., Strohmeyer, S., and Abendroth-Smith, J., 2003, "Development and evaluation of a biomechanics concept inventory," Sports biomechanics / International Society of Biomechanics in Sports, 2 (2), 267-277. DOI: $10.1080 / 14763140308522823$.

[6] Martin, A. J., 2006, "The Relationship Between Teachers' Perceptions of Student Motivation and Engagement and Teachers' Enjoyment of and Confidence in Teaching," Asia-Pacific Journal of Teacher Education, 34 (1), 73-93.

[7] Martin, V. Y., 2017, "Citizen science as a means for increasing public engagement in science," Science Communication, 39 (2), 142-168. 
Journal of Biomechanical Engineering

[8] Ministry of Education, 1999, Health and Physical Education in the New Zealand Curriculum, Wellington, New Zealand, Learning Media Limited. 
Table 1. Examples of themed open responses from post-workshop survey

\begin{tabular}{|c|c|}
\hline Theme & Teacher Feedback Responses \\
\hline \multirow[t]{3}{*}{ Learn From Others } & Networking opportunities with other schools - sharing ideas. \\
\hline & $\begin{array}{l}\text { I enjoyed attending the sessions with new faces and later } \\
\text { could learn and discuss together the concepts through group } \\
\text { discussions. }\end{array}$ \\
\hline & $\begin{array}{l}\text { Ideas from other teachers about their courses and some } \\
\text { teaching of [biomechanics] ideas for } Y 9 \text { to } 10 \text { students. }\end{array}$ \\
\hline \multirow[t]{2}{*}{ Networking } & Networking opportunities with other schools- sharing ideas. \\
\hline & Networking and idea sharing are invaluable. \\
\hline \multirow[t]{2}{*}{ New Knowledge } & Good activities that I can use in my class. \\
\hline & $\begin{array}{l}\text { Networking and communicating with other school. Time to } \\
\text { focus solely on biomechanics in a range of contexts and } \\
\text { hearing other ideas. }\end{array}$ \\
\hline
\end{tabular}




\section{Figure Captions List}

Fig. 1 Participants' assessment of how well biomechanical concepts were taught during their own secondary education. Data presented are distribution of participants' responses to survey questions. Seven mechanical concepts are given on the left. For each biomechanical concept, responses relate to how well the student teacher participant believed the concept taught in secondary school curriculum.

Fig. 2 Participants' assessment of their confidence in their knowledge of biomechanical concepts that were taught during their own secondary education. Data presented are distribution of participants' responses to survey questions. Seven mechanical concepts are given on the left. For each biomechanical concept, responses relate to how confident the student teacher participant was in their knowledge of the concept after being taught in secondary school. 
Journal of Biomechanical Engineering

Figure 1

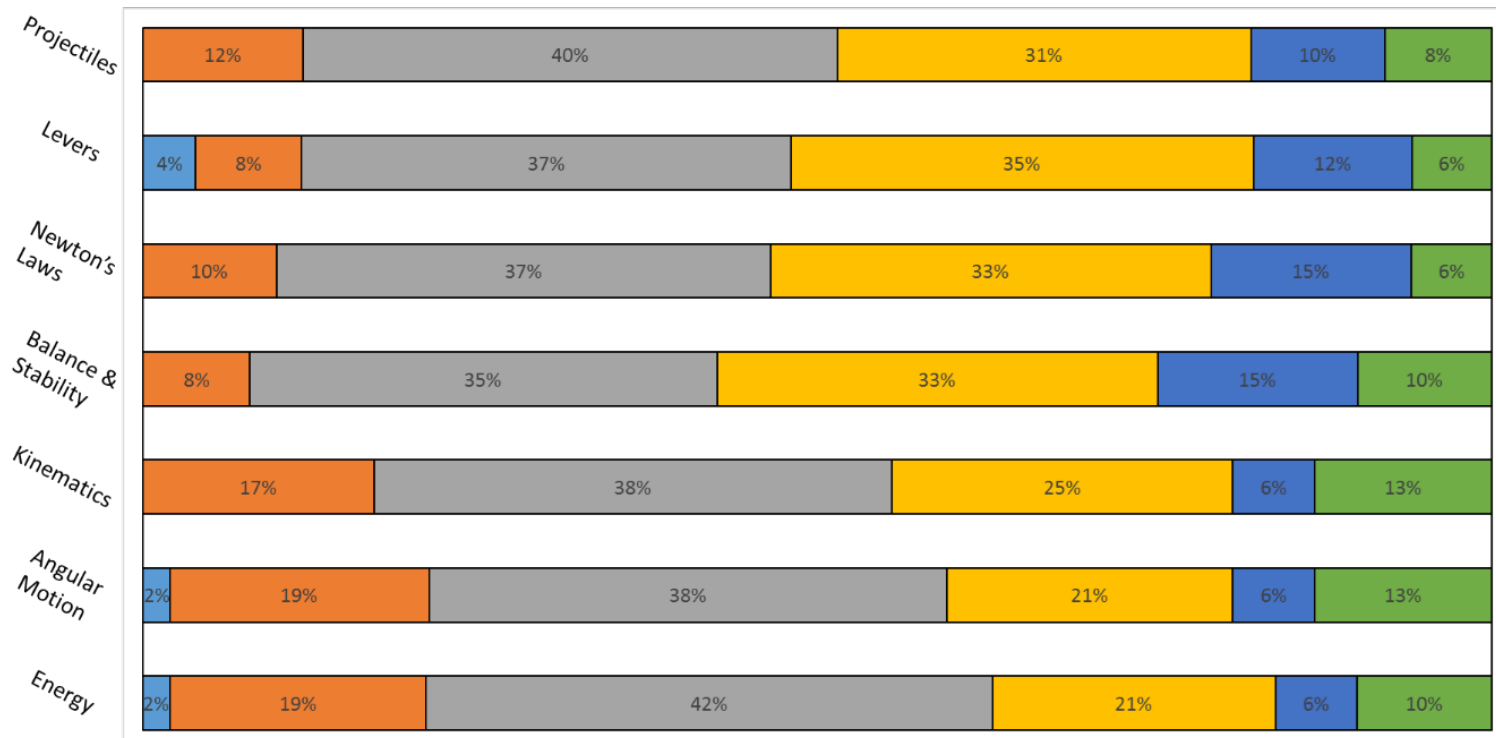

$\square$ 1. Very poorly taught $\square$ 1. Poorly taught $\square$ Neutral $\square$ 1. Taught Well $\square$ 1. Taught very well $\square$ Did not answer 
Journal of Biomechanical Engineering

\section{Figure 2}

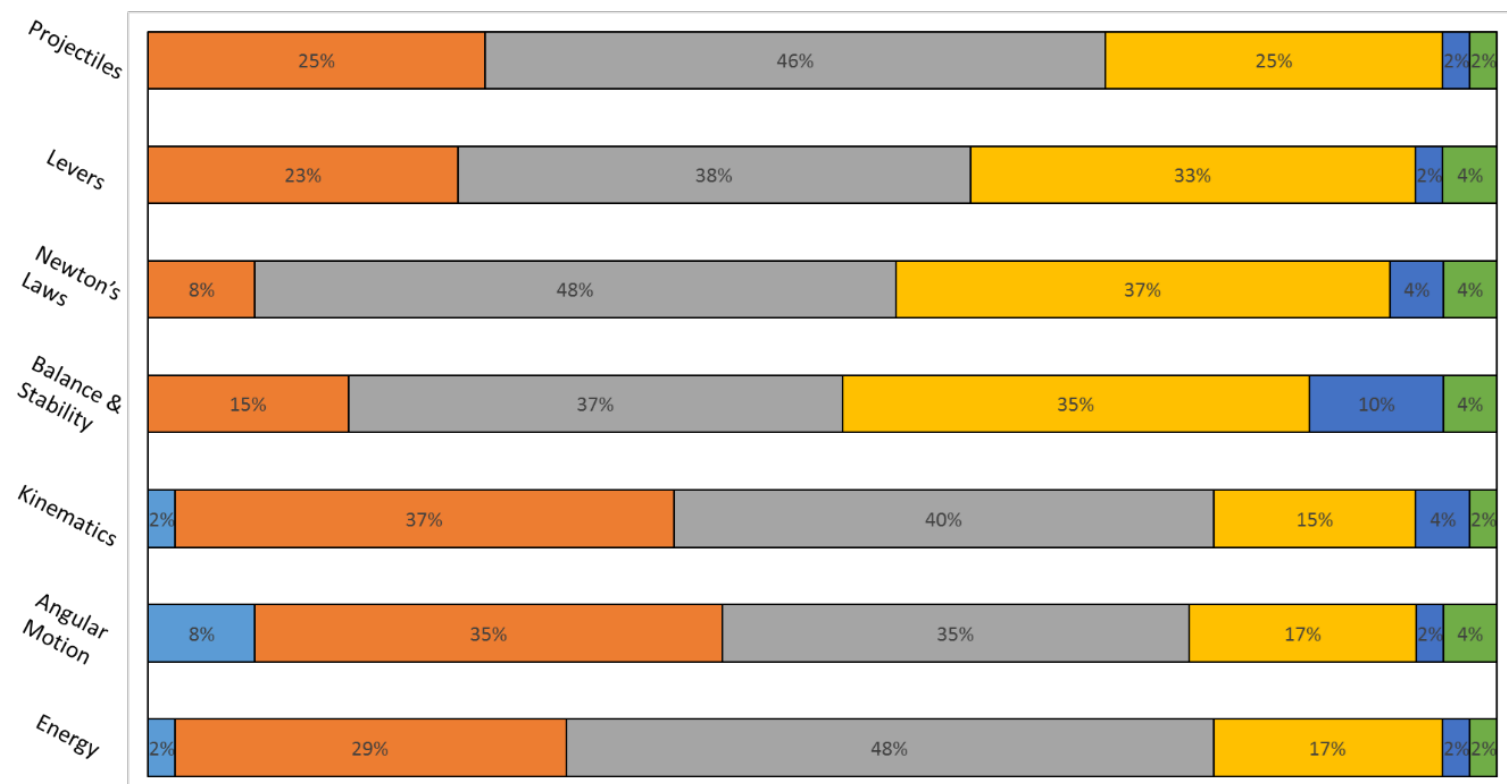

$\square$ Very unconfident $\square$ Not confident $\square$ Neutral $\square$ Confident $\square$ Very confident $\square$ Did not answer 